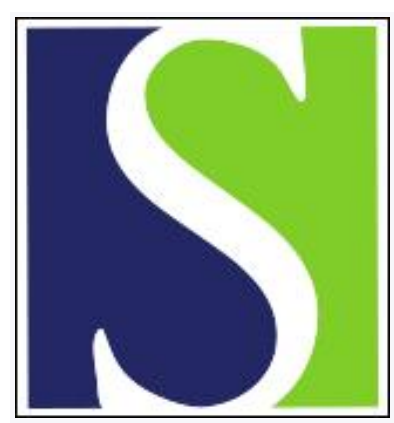

Scand J Work Environ Health 1985;11(1):21-26

https://doi.org/10.5271/sjweh.2258

Issue date: Feb 1985

Across-shift changes in the pulmonary function of meat-wrappers and other workers in the retail food industry. by Eisen EA, Wegman DH, Smith TJ

This article in PubMed: www.ncbi.nlm.nih.gov/pubmed/3992217

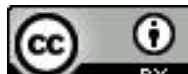




\title{
Across-shift changes in the pulmonary function of meat-wrappers and other workers in the retail food industry
}

\author{
by Ellen A Eisen, ScD, ${ }^{1}$ David $\mathrm{H}$ Wegman, MD, ${ }^{2}$ Thomas $\mathrm{J}$ Smith, $\mathrm{PhD}^{1}$
}

\begin{abstract}
EISEN EA, WEGMAN DH, SMITH TJ. Across-shift changes in the pulmonary function of meatwrappers and other workers in the retail food industry. Scand J Work Environ Health 11 (1985) 21-26. Pulmonary function was measured before, during, and after the end of the workshift in 83 workers in the retail food industry. All acute changes in forced expiratory volume in $1 \mathrm{~s}$ were standardized for lung size before the magnitude of the changes were compared between the workers exposed and unexposed to the use of hot wires for cutting plastic film. No association was found between acute drop in pulmonary function and either direct or indirect exposure in the absence of a history of asthma or allergy to inhaled materials. The borderline significance of an interaction term between exposure and asthma/allergy in a regression analysis suggests that workers with a history of asthma or atopy may have an acute response to hot-wire wrapping emissions.
\end{abstract}

Key terms: forced expiratory volume, meat-wrappers' asthma.

This report describes an examination of pre- and postshift changes in forced expiration among workers exposed or not exposed to hot-wire wrapping in the retail food industry. There have already been several studies of acute change in pulmonary function over the workday among employees in the retail food industry, in which no significant associations between work as a meat-wrapper and an acute drop in forced expiratory volume in $1 \mathrm{~s}\left(\mathrm{FEV}_{1.0}\right)$ were found $(3,6,7,8,10)$. None of the previous analyses adequately controlled, however, for differences in age, gender, height, or smoking between the exposed and unexposed subjects. Krumpe and co-workers (7) studied 58 full-time supermarket employees and 44 workers in a meat-packing plant and found that lung function improved over the shift among supermarket employees and that it improved during the week among meat-packers. In 1975 Polakoff et al (8) studied meat-wrappers in supermarkets and compared them to office personnel and store clerks. Wrappers were older, taller, smoked more, and included more women than the reference group. Without adjustment for confounding, no direct comparisons could be made between the two groups. The average drop in $\mathrm{FEV}_{1.0}$ among the meat-wrappers was $60 \mathrm{ml}$, a value significantly different from $0 \mathrm{ml}(\mathrm{p}<0.05)$. Jones \& Weill (6) studied 128 supermarket employees before and after a shift, 63 exposed to wrapping film and 65 unexposed. The proportions of subjects with abnormal before-after shift changes in $\mathrm{FEV}_{1.0}$ were

\footnotetext{
1 Department of Environmental Science and Physiology, Harvard School of Public Health, Boston, Massachusetts, the United States.

2 Center for Health Sciences, UCLA School of Public Health, Los Angeles, California, the United States.
}

Reprint requests to: Dr EA Eisen, Occupational Health Program, Harvard School of Public Health, 665 Huntington Avenue, Boston, MA 02115, USA. the same in these two groups. Of the exposed workers, 16 used hot wires and 41 used mechanical cutters. No significant differences in pulmonary function were found between these two subgroups of the cohort. In a health hazard evaluation of a meat-packing plant, Frederick et al (10) found that pulmonary function changes over the workday were greater among symptomatic, smoking production workers than among their nonsmoking asymptomatic co-workers. No significant differences were reported, however, between the 270 production workers and the reference group of 50 nonproduction workers. Brooks \& Vandervort (3) studied 24 meat-wrappers, 8 meatcutters, and 20 referents. Approximately one-third of the wrappers had chronic complaints of cough, sputum, and dyspnea on exertion; however, these workers did not have acute changes in lung function over the workshift.

The objective of this study was to evaluate the acute respiratory effects of polyvinyl chloride (PVC) emissions in the retail food industry. In particular, the aim was to improve on previous estimates of effect by controlling for confounding in the analysis.

\section{Subjects and methods}

\section{Study population}

In 1977 workers from four major foodstore chains in the greater Boston area were identified for a longitudinal study of the chronic respiratory effects of occupational exposures to PVC emissions. The four chains provided the names of their largest stores within a belt highway around the inner Boston suburbs. The study was limited to the 678 active employees who had been working in these large retail food stores for at least two years. Both the cross-sectional and longitudinal results of the entire cohort 
will be reported subsequently. The present report concerns the 83 employees who worked in the first six stores surveyed. They were studied for the presence of acute changes in pulmonary function during the workshift.

\section{Pulmonary function}

Forced expiratory volumes were measured before the start of the workshift (approximately 0700), in the middle of the shift (around 1100), and after the shift (about 1600). All the tests were performed on a Collins' survey spirometer which was volume and flow calibrated at the beginning and the end of the sixweek study period. The $\mathrm{FEV}_{1.0}$ was measured after back extrapolation to obtain zero time according to the method recommended by the American Thoracic Society (1). All spirometry was conducted without a noseclip and with the subject seated. Measurements of $\mathrm{FEV}_{1.0}$ were adjusted to body temperature and pressure saturated with water vapor (BTPS). A pulmonary function test was judged to be valid if the second largest $\mathrm{FEV}_{1.0}$ effort was within $200 \mathrm{ml}$ or $5 \%$ of the largest. If the effort was repeatable by this criterion, the maximum value was used in the analysis; otherwise the $\mathrm{FEV}_{1.0}$ was treated as a missing value.

The observed baseline pulmonary function values were compared with expected values derived from a prediction equation recently developed in the Six Cities' Air Pollution Study (4). This prediction equation is based on results from more than 14000 people in the general population over 25 years old and adjusts for age (with both a linear and quadratic term), gender, race, height, and smoking history (packyears).

\section{Medical questionnaire}

A medical questionnaire was administered to all subjects and included medical, smoking, and work histories. The following respiratory symptoms were defined from the questionnaire responses: frequent wheeze $=$ a wheezing or whistling sound in the chest on most days; chest tightness $=\mathrm{a}$ feeling of tightness in the chest or difficult breathing as often as once a week; chronic bronchitis = phlegm production twice a day for $4 \mathrm{~d}$ per week or any phlegm on getting up or first thing in the morning (in either case on most days, for as much as three months at a time, for at least three years).

Allergic and asthmatic histories were defined as follows: allergy to inhaled materials $=$ an allergic reaction to pollen, ragweed, dust, or animal dander reported to have been confirmed by a physician or told by a physician that subject has hay fever or allergic rhinitis; history of asthma = ever had asthma confirmed by a physician. A composite symptom variable was defined as the presence of either allergy or asthma or a family history of asthma, and referred to as asthma/allergy.

\section{Environmental exposure}

The nature of the exposures is described in detail in a separate report; however, the findings will be summarized here for completeness. Recent laboratory studies have shown that cutting PVC wrapping film with a hot wire produces concentrated airborne pulses of hydrogen chloride and particulate if the wire is hot enough (greater than $150^{\circ} \mathrm{C}$ ) (9). The emitted particulate is composed principally of the plasticizer dioctyl adipate (DOA), with pyrolysis fragments from the PVC and water-soluble chlorides. Laboratory and field studies of the air concentrations have indicated that the pulses of emissions from hot-wire cutting can reach the operator's breathing zone as short-duration, high-concentration peak exposures. The peaks lasted $5-10 \mathrm{~s}$ and had concentrations of $0.5-6 \mathrm{ppm}$ for hydrogen chloride and $1-15 \mathrm{mg} / \mathrm{m}^{3}$ for total aerosol. Although peak concentrations were high within a meter of the wire, they contained only small amounts of material, which were quickly dispersed beyond distances of only a few meters from the source. Because of both the small amounts of material emitted and the brevity of the peaks, the timeweighted average concentrations recorded for the personal samples were very low.

The average personal exposures of the meat-wrappers were found to be only twice as high as those of the meatcutters, despite differences in the qualitative nature of the two exposures. The meat-wrappers had "direct" exposure to peak concentrations, whereas there were no peaks in the "indirect" exposures of the meatcutters working in the same room. The exposures of other workers performing wrapping activities, such as delicatessen clerks, also had little or no exposure to peak concentrations. In addition to emissions from hot-wire wrap cutting, meat-wrappers and delicatessen workers who label packages with heatactivated labels are also occasionally exposed to emissions from the label adhesive when it is overheated. If the labels are overheated to the point of charring, a variety of toxic and irritant substances are emitted which include small amounts of aldehydes and phthalic anhydride.

For the purposes of this study of acute change in $\mathrm{FEV}_{1.0}$, current exposure was characterized in two ways, by exposure (yes/no) to hot-wire wrapping emissions and by current job title. No distinction was made within the first classification between workers with "direct" (wrapping) and "indirect" (in same room as wrapping) exposures. Four job titles were defined as follows: (i) meat-wrapper = worker spending more than half of the worktime wrapping in the meat room; (ii) meatcutter $=$ worker spending less than half of the (but more than zero) worktime wrapping in the meat room (iii) produce or delicatessen clerk = worker spending any time wrapping in the produce or delicatessen areas; and (iv) unexposed = workers neither wrapping nor working in a wrapping area nor working in a refrigerator or freezer environ- 
ment. Meat-wrapping was distinguished from delicatessen or produce wrapping because the latter two are performed in ambient temperatures, and the first in cold temperatures.

\section{Analytic method}

In adjusting for differences in lung size, the change in $\mathrm{FEV}_{1.0}$ over the workshift was standardized by the average $\mathrm{FEV}_{1.0}$ level during the day, ie, adjusted day change $=\left(\mathrm{PM} \mathrm{FEV}_{1.0}-\mathrm{AM} \mathrm{FEV}_{1.0}\right) / 0.5(\mathrm{AM}$ $\mathrm{FEV}_{1.0}+\mathrm{PM} \mathrm{FEV}_{1.0}$ ). The average level, rather than the initial level, was used to standardize the acute change in order to avoid bias (2), which would arise from measurement error in $\mathrm{FEV}_{1.0}$, whereby spuriously high AM values would be followed by apparently large negative acute changes (resulting in a spurious negative correlation between initial level and acute change).

General linear models were used to assess the association between 1-d change in $\mathrm{FEV}_{1.0}$ and the current exposure to wrapping fumes. Since expressing the change in $\mathrm{FEV}_{1.0}$ as a percentage of the mean value over the workday adjusts for lung size (essentially for sex and stature), gender and height did not need to be further considered in the analysis. The independent variables included in the regression and analysis of variance models were age, smoking (pack-years), the presence of asthma or allergy, an exposure variable, and an interaction term between hot-wire exposure and asthma/allergy.

\section{Results}

Only repeatable $\mathrm{FEV}_{1,0}$ values have been included in the analysis of AM, midday, and PM FEV ${ }_{1.0}$ levels and in the calculation of acute changes in $\mathrm{FEV}_{1.0}$ over the workshift. For example, the six subjects with nonreproducible preshift function tests have been excluded from the calculations of the average preshift $\mathrm{FEV}_{1.0}$ level, the average preshift level as a percentage of predicted, and the AM-noon and AM-PM acute changes. The eight individuals younger than 25 years were excluded from the analysis of the percentage of predicted $\mathrm{FEV}_{1.0}$ levels, but they are included in the analysis of acute changes. These exclusions explain the varying numbers of subjects included in the description of the cohort's characteristics (table 1).

Table 1. Characteristics of the acute study cohort. ( $\mathrm{FEV}_{1.0}=$ forced expiratory volume in $1 \mathrm{~s}, \Delta \mathrm{FEV} \mathrm{1}_{1.0}=$ the acute change in $\mathrm{FEV}_{1.0}, \mathrm{AM}=$ morning, $\mathrm{PM}=$ afternoon)

\begin{tabular}{|c|c|c|c|c|}
\hline & Number & Mean & $\begin{array}{l}\text { Standard } \\
\text { error }\end{array}$ & Percent \\
\hline \multicolumn{5}{|l|}{ General } \\
\hline Subjects & 83 & & & \multirow{4}{*}{41.5} \\
\hline Age (years) & . & 45.0 & 1.26 & \\
\hline Sex female & . & & & \\
\hline Pack-years of cigarette smoking & & 17.2 & 2.18 & \\
\hline Current smokers & 42 & . & & 50.6 \\
\hline Exsmokers & 18 & : & . & 21.7 \\
\hline Never smoked & 23 & : & . & 27.7 \\
\hline \multicolumn{5}{|l|}{ Respiratory history } \\
\hline Allergy to inhaled materials & 7 & .. & . & 8.4 \\
\hline Asthma & 3 & . & . & 3.6 \\
\hline Family history of asthma & 7 & . & . & 8.4 \\
\hline Asthma or allergies & 14 & . & . & 16.9 \\
\hline \multicolumn{5}{|l|}{ Respiratory symptoms } \\
\hline Frequent wheeze & 7 & . & . & 8.4 \\
\hline Chest tightness & 5 & . & . & 6.0 \\
\hline Chronic bronchitis & 5 & . & . & 6.0 \\
\hline \multicolumn{5}{|l|}{ Pulmonary function a } \\
\hline AM FEV $_{1.0}(\%$ predicted $)$ & 65 & 1.04 & 0.02 & . \\
\hline AM FEV 1.0 (I) & 73 & 3.161 & 0.095 & . \\
\hline Noon FEV $_{1.0}(\mathrm{l})$ & 77 & 3.141 & 0.092 & . \\
\hline PM FEV 1.0 (l) & 77 & 3.155 & 0.088 & . \\
\hline Nonrepeatable AM FEV 1.0 & 6 of 83 & . & . & 7.2 \\
\hline Nonrepeatable Noon FEV & 4 of 83 & . & . & 4.8 \\
\hline Nonrepeatable PM FEV $\mathrm{FV}_{1.0}$ & 2 of 81 & & & 2.5 \\
\hline$\triangle \mathrm{FEV}_{1.0}($ noon-AM) & 75 & -0.025 & 0.016 & . \\
\hline$\triangle \mathrm{FEV}_{1.0}(\mathrm{PM}$-noon) & 75 & -0.017 & 0.013 & : \\
\hline$\triangle \mathrm{FEV}_{1.0}(\mathrm{PM}-\mathrm{AM})$ & 73 & -0.060 & 0.017 & . \\
\hline Adjusted FEV ${ }_{1.0}$ (noon-AM) & 75 & -0.008 & 0.005 & . \\
\hline Adjusted FEV Fi. $^{1 .}$ (PM-noon) & 75 & -0.007 & 0.005 & . \\
\hline Adjusted FEV 1.0 (PM-AM) & 73 & -0.021 & 0.017 & . \\
\hline \multicolumn{5}{|l|}{ Exposure } \\
\hline \multicolumn{5}{|l|}{ Currently exposed to hot wire } \\
\hline wrapping & . & . & \multirow[b]{2}{*}{ : } & 48 \\
\hline Ever exposed to hot-wire & & & & \\
\hline wrapping directly & . & . & . & 47 \\
\hline
\end{tabular}


The group as a whole had an average preshift (AM) $\mathrm{FEV}_{1.0}$ which was $104 \%$ of the predicted value. Since smoking is already adjusted for in the Six Cities' prediction equation, a mean value of over $100 \%$ is probably evidence of a small "healthy worker effect," ie, working people are healthier on the average than their counterparts in the general population. The proportion of subjects with nonrepeatable pulmonary function tests decreased over the course of the day, from $7.2 \%$ in the morning, to $4.8 \%$ at noon, to less than $3 \%$ at the end of the workshift. This trend suggests that a learning effect was present, ie, practice improved the subjects' ability to perform repeatable lung function tests.

The average absolute drop in $\mathrm{FEV}_{1.0}$ for the entire day was $60 \mathrm{ml}$, or $2.1 \%$ of the preshift $\mathrm{FEV}_{1.0}$ level. Over $30 \%$ of the cohort had an absolute drop in FEV $_{1.0}$ over the workday that exceeded $100 \mathrm{ml}$, and six $(7.2 \%)$ had decreases greater than $10 \%$ of their preshift $\mathrm{FEV}_{1.0}$ level. The morning change (between the AM and midday measurements) was slightly larger than the afternoon change in both absolute terms, and also as a percentage of the $\mathrm{FEV}_{1,0}$ level. At the time of testing, $48 \%$ of the workers were either directly or indirectly exposed to hot-wire wrapping emissions.

In table 2, the cohort is shown divided into those with and without current exposure (direct or indirect) to hot-wire wrapping. The two groups have the same mean age, pack-years of cigarette smoking, percentage of females, and prevalence of subjects with either asthma or an allergy to inhaled materials. Exposed subjects had a greater prevalence of family his- tory of asthma, while the unexposed subjects reported allergy more frequently. Since the mean values of the major covariates were the same in the exposed and unexposed groups, $t$-tests were used to test whether the AM FEV $V_{1.0}$ level or the acute change differed between the two groups. None of the differences were significant. A decrease in the numbers of nonrepeatable lung function tests from morning to afternoon was apparent in both groups.

Of the 43 not currently exposed workers, $25 \%$ had been exposed to hot-wire wrapping emissions at some point in the past. Among the 27 individuals who had never been exposed at any time, the mean acute change was $-2.7 \%$ of the initial FEV $_{1.0}$ level. Four of the 43 were currently wrapping with cool rods. These four were indistinguishable from the rest with respect to acute change in lung function or any covariate.

The cohort was divided according to current job title (table 3). Meat-wrappers had direct exposure to either hot-wire or cool-rod wrapping, while meatcutters had indirect exposure. Delicatessen and produce clerks had exposure to hot-wire or cool-rod wrapping, but, unlike workers in the meat room, their exposures occurred at ambient temperatures. In an analysis of variance model, the adjusted acute changes did not vary significantly between the meat-wrappers, the meatcutters, the delicatessen produce clerks, and the unexposed workers after adjustment for age and the presence of asthma or allergy. When the cohort was divided by current smoking habits, current and exsmokers did not have larger mean day changes in $\mathrm{FEV}_{1.0}$ than employees who had never

Table 2. Characteristics for those with and without current exposure to hot-wire wrapping. (FEV ${ }_{1.0}=$ forced expiratory volume in $1 \mathrm{~s}, \mathrm{AM}=$ morning, $\mathrm{PM}=$ afternoon)

\begin{tabular}{|c|c|c|c|c|c|c|c|c|}
\hline & \multicolumn{4}{|c|}{ Hot wire exposure } & \multicolumn{4}{|c|}{ No hot wire exposure } \\
\hline & Number & Mean & $\begin{array}{l}\text { Standard } \\
\text { error }\end{array}$ & Percent & Number & Mean & $\begin{array}{l}\text { Standard } \\
\text { error }\end{array}$ & Percent \\
\hline Subjects & 40 & . & . & . & 43 & . & . & . \\
\hline Sex female & . & . & . & 40.0 & . & . & . & 44.2 \\
\hline Pack-years of cigarette smoking & . & 17.3 & 2.82 & . & . & 17.2 & 3.30 & . \\
\hline Age (years) & . & 44.9 & 1.81 & . & . & 45.2 & 1.80 & . \\
\hline \multicolumn{9}{|l|}{ Respiratory history } \\
\hline $\begin{array}{l}\text { Asthma } \\
\text { Family history of asthma } \\
\text { Allergy to inhaled material } \\
\text { Asthma or allergy }\end{array}$ & : & $\dot{.}$ & $\dot{.}$ & $\begin{array}{r}2.5 \\
12.5 \\
7.5 \\
17.5\end{array}$ & $\dot{.}$ & $\dot{.}$ & $\dot{.}$ & $\begin{array}{r}4.7 \\
4.7 \\
11.6 \\
16.3\end{array}$ \\
\hline \multicolumn{9}{|l|}{ Respiratory symptoms } \\
\hline $\begin{array}{l}\text { Chest tightness } \\
\text { Wheezing } \\
\text { Chronic bronchitis }\end{array}$ & . & . & . & $\begin{array}{r}12.5 \\
15.0 \\
2.5\end{array}$ & $\dot{.}$ & . & $\dot{.}$ & $\begin{array}{l}\overline{2.3} \\
9.3\end{array}$ \\
\hline \multicolumn{9}{|l|}{ Pulmonary function } \\
\hline $\begin{array}{l}\text { Acute change in } \mathrm{FEV}_{1.0^{\mathrm{a}}} \\
\text { Adjusted acute change }\end{array}$ & $\cdot$ & $\begin{array}{l}-0.037 \\
-0.015\end{array}$ & $\begin{array}{l}0.023 \\
0.008\end{array}$ & . & . & $\begin{array}{l}-0.081 \\
-0.028\end{array}$ & $\begin{array}{l}0.026^{*} \\
0.008^{* *}\end{array}$ & . \\
\hline $\begin{array}{l}\text { Nonrepeatable AM FEV } \\
\text { Nonrepeatable noon } \text { FEV }_{1.0}\end{array}$ & $\begin{array}{l}3 \\
3\end{array}$ & : & : & $\begin{array}{l}7.5 \\
7.5\end{array}$ & $\begin{array}{l}3 \\
1\end{array}$ & $\cdot$ & $\dot{.}$ & 7.3 \\
\hline $\begin{array}{l}\text { Nonrepeatable PM FEV } \\
\% \text { predicted FEV } 10 \text { AM }\end{array}$ & 1 & i.04 & 0.03 & $\begin{array}{l}2.5 \\
.\end{array}$ & 1 & 1.04 & $0.03^{* * *}$ & 2.4 \\
\hline
\end{tabular}

a PM FEV
${ }^{*} \mathrm{t}=-1.0, \mathrm{AM} \mathrm{FEV}_{1.0 \cdot}$
$\mathrm{A}=0.21 ;{ }^{*} \mathrm{t}=-1.10, \mathrm{p}=0.27 ;{ }^{* * *} \mathrm{t}=0.25, \mathrm{p}=0.80$ 
Table 3. Acute change in $\mathrm{FEV}_{1.0}$ by current job. $\left(\mathrm{N}=\right.$ number, $\mathrm{SE}=$ standard error, $\%=$ percent, $\mathrm{FEV}_{1.0}=$ forced expiratory volume in $1 \mathrm{~s}, \mathrm{AM}=$ morning, $\mathrm{PM}=$ afternoon)

\begin{tabular}{|c|c|c|c|c|c|c|c|c|c|c|c|c|c|c|c|c|}
\hline & \multicolumn{4}{|c|}{ Meat wrappers } & \multicolumn{4}{|c|}{ Meatcutters } & \multicolumn{4}{|c|}{$\begin{array}{l}\text { Delicatessen/ } \\
\text { produce clerks }\end{array}$} & \multicolumn{4}{|c|}{ Unexposed workers } \\
\hline & $N$ & Mean & SE & $\%$ & $\mathrm{~N}$ & Mean & SE & $\%$ & $\mathrm{~N}$ & Mean & SE & $\%$ & N & Mean & SE & $\%$ \\
\hline $\begin{array}{l}\text { Subjects } \\
\text { Acute change in }\end{array}$ & 14 & . & . & . & 17 & . & . & . & 12 & . & . & . & 40 & - & . & . \\
\hline $\begin{array}{l}\mathrm{FEV}_{1.0} \text { (I) } \\
\text { Adjusted acute change }\end{array}$ & . & -0.052 & 0.027 & . & . & -0.031 & 0.055 & . & . & -0.041 & 0.032 & . & . & -0.079 & 0.026 & . \\
\hline in $\mathrm{FEV}_{1.0}$ & . & -0.023 & 0.011 & . & . & -0.007 & 0.017 & . & . & -0.016 & 0.011 & . & . & -0.027 & 0.009 & . \\
\hline $\begin{array}{l}\mathrm{FEV}_{1.0} \% \text { predicted } \\
\text { Nonrepeatable }\end{array}$ & . & 1.02 & 0.05 & . & . & 1.03 & 0.04 & . & . & 1.03 & 0.058 & . & . & 1.03 & 0.03 & . \\
\hline $\begin{array}{l}\text { AM FEV } 1.0 \\
\text { Nonrepeatable noon }\end{array}$ & - & . & . & . & 3 & . & . & 17.6 & 1 & . & . & 8.3 & 2 & . & . & 5 \\
\hline $\begin{array}{l}\text { FEV }_{1.0} \\
\text { Nonrepeatable PM }\end{array}$ & - & . & . & . & 2 & . & . & 11.8 & 1 & . & . & 8.3 & 1 & . & . & 2.5 \\
\hline FEV $_{1.0}$ & - & . & . & & 1 & . & . & 5.9 & - & . & . & & 1 & . & . & 2.6 \\
\hline $\begin{array}{l}\text { Sex female } \\
\text { Pack-years of }\end{array}$ & . & . & . & 100 & . & . & . & - & . & . & . & 20 & . & . & . & 45 \\
\hline cigarette smoking & . & 12.8 & 4.1 & . & . & 21.4 & 4.9 & . & . & 13.5 & 4.7 & & 18.1 & . & 3.5 & . \\
\hline Chest tightness & . & . & . & 21.4 & . & . & . & - & . & . & . & 20 & . & . & . & - \\
\hline $\begin{array}{l}\text { Asthma } \\
\text { Allergy to inhaled }\end{array}$ & . & . & . & - & . & . & . & 5.9 & . & . & . & 0.08 & . & . & . & 2.5 \\
\hline $\begin{array}{l}\text { materials } \\
\text { Age (years) }\end{array}$ & . & 40.7 & 3.4 & 14.3 & . & 49.8 & 1.5 & 11.8 & : & 38.3 & 4.1 & 8.3 & . & 46.6 & $1 . \dot{ }$ & 5 \\
\hline
\end{tabular}

smoked, $-1.6 \%,-2 \%$, and $-2.8 \%$ of the $\mathrm{FEV}_{1.0}$ level, respectively. All three standard errors were close to $1 \%$.

To look more carefully at the association between wrapping specifically with a hot-wire and acute $\mathrm{FEV}_{1.0}$ drop, we used a linear regression model in which the adjusted acute change in FEV $_{1.0}$ was the outcome variable. The independent variables in the model were age, smoking, the presence of asthma or allergy, current exposure to hot-wire wrapping, and an interaction term between exposure and asthma/allergy. With the exception of the interaction between exposure and asthma/allergy, which was of borderline significance $(p=0.06)$, no other covariate was associated significantly with the change in $\mathrm{FEV}_{1.0}$ (table 4). The negative parameter estimate for the interaction term suggests that, if a worker had an allergy or asthma and was currently exposed to hot-wire wrapping, that individual was likely to have a greater decrease in $\mathrm{FEV}_{1.0}$ over the workday than a worker who had no allergy or asthma and was not exposed to hot-wire wrapping fumes.

\section{Discussion}

Data have recently been reported suggesting that individuals in working populations who do not succeed in performing repeatable pulmonary function tests may be less healthy than their co-workers (5). Therefore the six subjects without repeatable preshift function tests were compared to the rest of the cohort with respect to the major outcome variables and covariates. They were found to have a lower average $\mathrm{FEV}_{1.0}$ as a percentage of the predicted ( 99 versus $103 \%$ ) although the validity of this comparison may be compromised because the $\mathrm{FEV}_{1.0}$ values of these
Table 4. Regression analysis of the adjusted acute change in forced expiratory volume in $1 \mathrm{~s},{ }^{a}$

\begin{tabular}{lrrr}
\hline Independent variables & $\begin{array}{c}\text { Parameter } \\
\text { estimate }\end{array}$ & $\mathrm{t}$ & $\mathrm{PR}>\mathrm{t}$ \\
\hline Intercept & 0.0247 & 0.70 & 0.4839 \\
Age & -0.0010 & -1.43 & 0.1600 \\
Pack-years of & & & \\
cigarette smoking & -0.0002 & -0.75 & 0.4562 \\
Hot-wire exposure & 0.0218 & 1.62 & 0.1113 \\
Asthma/allergy & 0.0385 & 1.22 & 0.2267 \\
How-wire exposure & & & \\
and asthma/allergy & -0.076 & 1.92 & 0.0601 \\
\hline
\end{tabular}

a Sum of squared errors $=0.149$, degrees of freedom of the squared errors $=59, F=1.42, \mathrm{pr}>F=0.229, R^{2}=0.11$.

six subjects may not have been maximal efforts. The nonrepeaters also had more asthma and more allergy than the rest of the cohort; two of the six ( $33 \%$ ) who failed to perform repeatable tests reported asthma compared to $1.3 \%$ of their co-workers, and another one of the six had allergy. The prevalence of the composite asthma/allergy symptom was therefore $50 \%$ in this group. The proportion of subjects with nonrepeatable tests was the same among those exposed and those not exposed to hot-wire wrapping (table 2). Therefore, the parameter estimates in the dose-response model (table 4) were not biased by the exclusion of these six individuals.

Overall, the 40 workers currently exposed to hotwire wrapping did not have more substantial pre- or postshift drops in $\mathrm{FEV}_{1.0}$ than their unexposed coworkers. However, the borderline significance of the interaction term in the regression analysis suggests that a larger acute drop may be associated with exposure to hot-wire wrapping if the workers also have a history of allergy to inhaled materials. 


\section{Acknowledgments}

This study was supported by a research agreement between the Joint Labor Management Committee of the Retail Food Industry, Inc, and the Harvard School of Public Health and by grant 1 R23 ES 03023-01 from the National Institute of Environmental Health Sciences.

The authors wish to thank Dr LJ Fine and Ms A Siracusa for their early contributions to the analysis of these data. We could also like to thank Dr IA Greaves for his helpful comments on an earlier draft.

\section{References}

1. American Thoracic Society. ATS statement - Snowbird workshop on standardization of spirometry. Am Rev Respir Dis 119 (1979) 831-838.

2. Blomqvist $\mathbf{N}$. On the relation between change and initial value. J Am Stat Assoc 72 (1977) 746-749.

3. Brooks SM, Vandercort R. Polyvinyl chloride film thermal decomposition products as an occupational illness. J Occup Med 19 (1977) 192-196.
4. Dockery DW, Speizer FE, Ware JH, Ferris BG Jr. Normal values for simple tests of pulmonary function in white adults. Am Rev Respir Dis (in press).

5. Eisen EA, Wegman DH, Louis TA. Selection effects in a prospective study of Vermont granite workers. Am Rev Respir Dis 128 (1983) 587-591.

6. Jones RN, Weill H. Respiratory health and polyvinyl chloride fumes. J Am Med Assoc 237 (1977) 1826. (Letter to the editor).

7. Krumpe PE, Finley TN, Martinez N. The search for expiratory obstruction in meatwrappers studied on the job. Am Rev Respir Dis 119 (1979) 611-618.

8. Polakoff PL, Lapp NL, Reger R. Polyvinyl chloride pryolysis products. Arch Environ Health 30 (1975) $269-271$.

9. Smith TJ, Cafarella JJ, Chelton C, Crowley S. Evaluation of respiratory exposures during commercial meat wrapping - Emissions from simulated operations using wrap. Am Ind Hyg Assoc J 44 (1983) 176-183.

10. US Department of Health, Education and Welfare. Health hazard evaluation determination report. Denver, CO 1981. (HE 79-011-1011).

Received for publication: 6 August 1984 